\title{
INHIBITION OF ALVEOLAR MACROPHAGE 5-LIPOXYGENASE METABOLISM BY AURANOFIN*
}

\author{
MARC Peters-Golden $\dagger$ and CANDACe Shelly \\ Division of Pulmonary and Critical Care Medicine, Department of Internal Medicine, University of \\ Michigan and Veterans Administration Medical Centers, Ann Arbor, MI, U.S.A.
}

(Received 18 April 1988; accepted 26 September 1988

\begin{abstract}
We have examined the effect of the oral gold compound auranofin (AF) on calcium ionophore A23187-induced arachidonic acid metabolism in the rat alveolar macrophage. Both reverse-phase high performance liquid chromatographic and radioimmunoassay analyses revealed that AF dose-dependently inhibited leukotriene $\mathbf{B}_{4}$ and 5-hydroxyeicosatetraenoic acid synthesis in a parallel fashion with an $\mathrm{IC}_{50} \sim 4.3 \mu \mathrm{g} / \mathrm{ml}$. At the same time, AF augmented A23187-induced arachidonate release and cyclooxygenase metabolism. A possible mechanism for the inhibition of 5-lipoxygenase was suggested by the capacity of AF to dose-dependently deplete ATP $\left(\mathrm{IC}_{50} \sim 5.9 \mu \mathrm{g} / \mathrm{ml}\right)$, a cofactor for 5-lipoxygenase. These data indicate that, at therapeutic concentrations, AF acts in vitro as a selective inhibitor of macrophage 5-lipoxygenase metabolism. This likely represents an important mechanism of action of $\mathrm{AF}$ in chronic inflammatory disorders.
\end{abstract}

Chrysotherapy has well-established efficacy in the treatment of rheumatoid arthritis [1]. In addition, gold salts have been shown to attenuate airway responsiveness in animals [2] as well as humans [3], and to decrease symptom scores and medication requirements in patients with asthma $[3,4]$. It is generally recognized that chronic inflammation plays a prominent role in the pathogenesis of both rheumatoid arthritis [5] and asthma [6], and prominent among the many potential mediators of inflammation which have been suggested to be important in these conditions are the eicosanoids, a group of oxygenated derivatives of arachidonic acid (AA) [7]. Recent studies have demonstrated that auranofin (AF), an oral gold compound, inhibits the synthesis of leukotrienes, potent pro-inflammatory 5-lipoxygenase metabolites of $\mathrm{AA}$, in human blood neutrophils $[8,9]$, basophils [10], and lung mast cells [10].

Although the macrophage is thought to play a central role in chronic inflammatory disorders [11], has the capacity to release relatively large amounts of cyclooxygenase and 5-lipoxygenase eicosanoids [12], and is a putative target cell for the anti-inflammatory effects of gold [13], we are aware of no information on the modulation by gold compounds of macrophage-derived eicosanoid synthesis. We therefore examined the effect of $\mathrm{AF}$ on calcium ionophore A23187-induced AA metabolism in the rat alveolar macrophage (AM), a cell which produces large amounts of 5-lipoxygenase metabolites including both leukotrienes $\mathrm{B}_{4}\left(\mathrm{LTB}_{4}\right)$ and $\mathrm{C}_{4}\left(\mathrm{LTC}_{4}\right)$ [14]. Our results indicated that AF inhibits AM 5lipoxygenase metabolism at therapeutic concen-

\footnotetext{
* Work was supported by grants from the Research Service of the Veterans Administration and the National Institutes of Health (HL-01638).

+ Correspondence: Marc Peters-Golden, M.D., 3916 Taubman Center, Box 0360, University of Michigan Medical Center, Ann Arbor, MI 48109-0360.
}

trations, and they suggest that the mechanism of this inhibitory action may involve the depletion of cellular ATP, a cofactor for the 5-lipoxygenase enzyme $[15,16]$.

\section{METHODS}

Macrophage isolation and culture. Respiratory disease-free $125-150 \mathrm{~g}$ female Wistar rats were obtained from Charles River (Portage, MI) and housed under specific pathogen-free conditions. Following anesthesia with intraperitoneal sodium pentobarbital, lungs were surgically excised and lavaged as previously described [17]. Lavage fluid, as well as Hanks' balanced salt solution (HBSS) (GIBCO, Grand Island, NY) and medium 199 with modified Earle's salts (M199) (GIBCO) all contained $100 \mathrm{units} / \mathrm{ml}$ penicillin, $100 \mu \mathrm{g} / \mathrm{ml}$ streptomycin, and $0.25 \mathrm{mg} / \mathrm{ml}$ amphotericin B (Antibiotic-Antimycotic Solution, Sigma Chemical Co., St. Louis, MO). Cells $\left(2 \times 10^{6}\right)$ suspended in $1.5 \mathrm{ml}$ of M199 were plated in $35 \times 10 \mathrm{~mm}$ plastic culture dishes (Falcon Plastics, Oxnard, CA) and cultured at $37^{\circ}$ in a humidified atmosphere of $5 \% \mathrm{CO}_{2}$ in air. After $1 \mathrm{hr}$, non-adherent cells were removed by washing twice with HBSS. The resultant adherent cell population has been found to contain $95 \%$ AM by morphologic criteria and esterase staining [17] with viability exceeding $90 \%$ as assessed by trypan blue exclusion. Macrophage monolayers were then cultured overnight $(16 \mathrm{hr})$ in M199 containing $10 \%$ heat-inactivated newborn calf serum (NCS) (GIBCO) in the presence or absence of radiolabeled AA prior to experimental incubations. Following overnight culture, these monolayers have been found to contain approximately $8.5 \mu \mathrm{g}$ DNA [17] and $100 \mu \mathrm{g}$ protein [14].

Prelabeling of macrophage cultures. In selected experiments, cellular lipids were prelabeled by including $0.2 \mu \mathrm{Ci}$ of $\left[1-{ }^{14} \mathrm{C}\right] \mathrm{AA}$ (sp. act. $54-57 \mathrm{mCi}$ ) mmol, Dupont-New England Nuclear, Boston, MA) in the medium during overnight culture. To remove 
unincorporated label, cells were washed with HBSS, incubated for an additional hour with M199 containing $10 \%$ NCS, and washed again prior to experimental incubations. The uptake of radiolabel by macrophage cultures, determined as described previously [17], was routinely $35-40 \%$.

Incubations with A23187 and AF. Auranofin, provided by Smith Kline \& French Laboratories (Philadelphia, PA), was prepared as a stock solution at $20 \mathrm{mg} / \mathrm{ml}$ in DMSO, and diluted in M199 to final desired concentrations. Following overnight incubation, duplicate cultures of labeled or unlabeled AM were washed twice with HBSS and preincubated for $15 \mathrm{~min}$ with $1 \mathrm{ml}$ of M199 alone or M199 containing $\mathrm{AF}$ at concentrations ranging from 0.5 to $100 \mu \mathrm{g} / \mathrm{ml}$. Then calcium ionophore A23187 (Calbiochem-Behring Corp., LaJolla, CA), $10 \mu \mathrm{M}$, was added and the incubation continued for an additional $30 \mathrm{~min}$. The final concentration of DMSO in all cultures was $0.5 \%$, which did not affect cell viability or eicosanoid synthesis.

Eicosanoid extractions. Eicosanoids were extracted from culture medium using Sep-pak $C_{18}$ cartridges (Waters Associates, Milford, MA) according to the method of Westcott $e t$ al. [18]. Methanol/ water $(80: 20, \mathrm{v} / \mathrm{v})$ eluates containing eicosanoids were dried under nitrogen and stored at $-70^{\circ}$. Recoveries for this extraction procedure, assessed using tritiated standards (Dupont-New England Nuclear) added to M199, were $65-70 \%$ for $\mathrm{LTB}_{4}$, $\mathrm{LTC}_{4}$, and thromboxane $\mathrm{B}_{2}\left(\mathrm{TxB}_{2}\right.$, the stable breakdown product of $\mathrm{TxA}_{2}$ ) [19].

Radioimmunoassays. $\mathrm{LTB}_{4}, \mathrm{LTC}_{4}$, and $\mathrm{TxB}_{2}$ in medium from unlabeled AM cultures were quantitated by radioimmunoassays (RIA) performed by the Ligand Core Laboratory of the University of Michigan Diabetes Research and Training Center. Dried lipid extracts were dissolved in $1 \mathrm{ml}$ of phosphate-buffered saline containing $0.1 \%$ gelatin (pH 7.4), and 100- $\mu$ l aliquots were assayed in duplicate for each sample. The antibody sources and cross-reactivities, and the assay sensitivities for these RIA have been described previously [14]. The specificities of the RIA have been confirmed by analyses utilizing reverse-phase high performance liquid chromatography (RP-HPLC) [20,21]. In all cases, quantities of immunoreactive eicosanoids reported were corrected for recovery.

Eicosanoid separation by reverse-phase high performance liquid chromatography. For separation of $\left[{ }^{14} \mathrm{C}\right] \mathrm{AA}$ metabolites produced by prelabeled AM, lipid extracts of pooled medium from duplicate cultures were dissolved in $500 \mu \mathrm{l}$ of acetonitrile/water/ triffuoroacetic acid $(33: 67: 0.1$, by vol.) and subjected to RP-HPLC using a Waters HPLC system equipped with a Waters $5 \mu \mathrm{m}$ Bondapak $\mathrm{C}_{18}$ column $(30 \times 0.4 \mathrm{~cm})$ eluted with acetonitrile/water/ trifluoroacetic acid at $1 \mathrm{ml} / \mathrm{min}$, as previously described [20]. Using this system, cyclooxygenase metabolites are eluted during an initial isocratic phase (33:67:0.1, by vol.), followed by lipoxygenase metabolites and free AA, which elute during a stepwise gradient increase of acetonitrile to 100:0:0.1 (by vol.). The eluate was monitored continuously for UV absorbance [ $210 \mathrm{~nm}$ for cyclooxygenase products and free AA, $280 \mathrm{~nm}$ for LTs, and $235 \mathrm{~nm}$ for mono- hydroxyeicosatetraenoic acids (HETEs)]. Authentic $\mathrm{TxB}_{2}$, prostaglandin (PG) $\mathrm{D}_{2}, \mathrm{PGE}_{2}, \mathrm{PGF}_{2 \alpha}$, and 6keto-PGF ${ }_{1 \alpha}$ were gifts of Dr. J. Pike (Upjohn Co. Kalamazoo, MI), and lipoxygenase standards $\mathrm{LTB}_{4}$, LTC $_{4}, 5$-HETE, 12-HETE, and 15-HETE of Dr. J. Rokach (Merck Frosst, Inc., Ouebec. Canada). Authentic 12-hydroxy-5, 8, 10-heptadecatrienoic acid (HHT) was obtained from the Cayman Chemical Co. (Ann Arbor, MI), and arachidonic acid from $\mathrm{Nu}$-Chek Prep, Inc. (Elysian, MN). Eluate fractions of $1 \mathrm{ml}$ were collected, and radioactivity was quantitated in $6 \mathrm{ml}$ of ACS scintillant (Amersham. Arlington Heights, IL) using a Beckman LS1801 scintillation counter (Beckman Instruments, Inc., Fullerton, CA) with a counting efficiency for ${ }^{14} \mathrm{C}$ of approximately $75 \%$. Radiolabeled eicosanoids were identified by their co-elution with authentic standards.

Adenosine triphosphate assay. Cellular ATP was determined by the luciferase-luciferin assay [22], as previously described [19]. Briefly, after experimental incubation, culture medium was removed and monolayers were scraped with a rubber policeman into iced $10 \mathrm{mM}$ potassium phosphate, $4 \mathrm{mM} \mathrm{MgSO}_{4}$ buffer, $\mathrm{pH}$ 7.4. Cell suspensions were placed in a 90 $95^{\circ}$ water bath for $4 \mathrm{~min}$, and then on ice until assay, within $4 \mathrm{hr}$. At the time of assay, an aliquot of cell suspension was added to $50 \mathrm{mM} \mathrm{Na}{ }_{2} \mathrm{HAsO}_{4}, 20 \mathrm{mM}$ $\mathrm{MgSO}_{4}$ buffer, $\mathrm{pH} 7.4$, in a glass scintillation vial. Fifty microliters of luciferase-luciferin (Sigma), reconstituted in sterile glycine buffer, was added to the assay mixture, and light emission was quantitated immediately in a Beckman LS1801 counter using the single photon monitor mode. Standard curves of $\log$ $\mathrm{cpm}$ versus log [ATP] were linear over the range $10^{-9}$ to $10^{-6} \mathrm{M}$ ATP

Glutathione assay. Monolayers were deproteinated with $0.7 \mathrm{M}$ perchloric acid, neutralized with $2 \mathrm{M}$ potassium hydroxide, and intracellular total (reduced plus oxidized) glutathione was quantitated by the glutathione reductase assay [23], recording the change in absorbance at $412 \mathrm{~nm}$ over time with a Beckman model 35 spectrophotometer. The details of the cellular processing and of the assay itself were as previously described [14].

Data analysis. All data are expressed as means $\pm \mathrm{SE}$. In all cases, immunoreactive eicosanoid levels in medium and cellular ATP and glutathione contents were determined in duplicate culture plates for each experimental condition and the average calculated to yield a single data point. The effect of AF on A23187-stimulated eicosanoid synthesis is expressed as the percent of the eicosanoid level found in cultures stimulated with A23187 alone, after correction for control levels of production. Similarly, the effects of AF on cellular content of ATP and glutathione are expressed as the percent of the content of cells incubated with A23187 alone.

\section{RESULTS}

A23187-induced AA metabolism. Figure 1A depicts a representative $\left[{ }^{14} \mathrm{C}\right]$ eicosanoid RP-HPLC elution profile from AM cultures incubated for 30 min with $10 \mu \mathrm{M} \mathrm{A} 23187$ alone. The major peaks of radioactivity co-eluted with authentic standards 

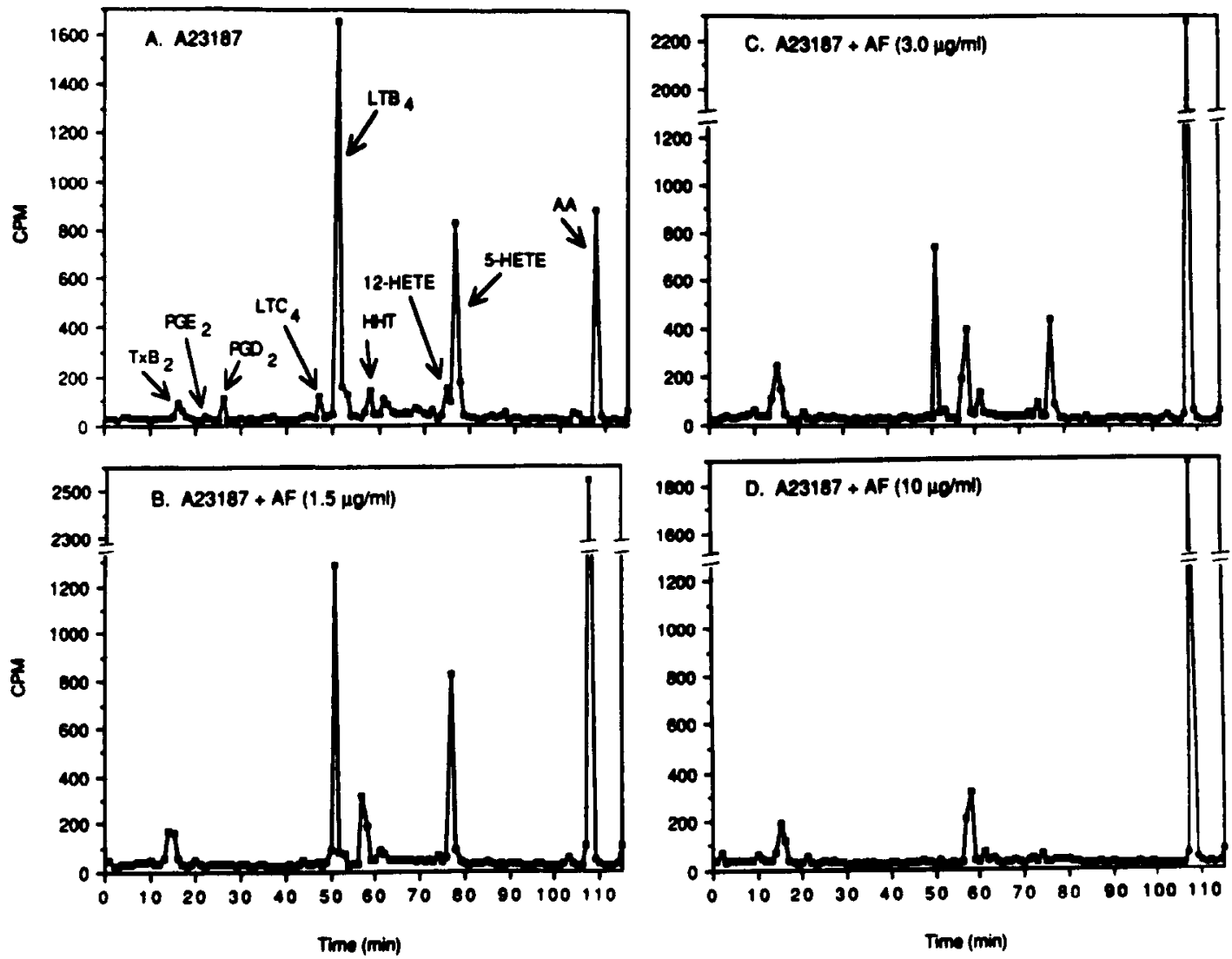

Fig. 1. RP-HPLC analysis of radiolabeled eicosanoids in culture medium from $\left[{ }^{14} \mathrm{C}\right] \mathrm{AA}$-prelabeled AM. Macrophages were incubated for 30 min with $10 \mu \mathrm{M}$ A23187 alone (A), or A23187 in the presence of AF at $1.5 \mu \mathrm{g} / \mathrm{ml}$ (B), $3 \mu \mathrm{g} / \mathrm{ml}$ (C), or $10 \mu \mathrm{g} / \mathrm{ml}$ (D). Retention times of authentic standards are indicated by arrows.

Table 1. Immunoreactive eicosanoid synthesis by unstimulated and A23187-stimulated alveolar macrophages in the absence of $\mathrm{AF}$

\begin{tabular}{lccc}
\hline & \multicolumn{3}{c}{ Eicosanoid (ng/plate) } \\
& LTC $_{4}$ & LTB $_{4}$ & TxB $_{2}$ \\
\hline Control & $0.29 \pm 0.01$ & $0.10 \pm 0.02$ & $0.52 \pm 0.09$ \\
A23187 & $11.30 \pm 4.33$ & $41.90 \pm 7.02$ & $1.95 \pm 0.03$
\end{tabular}

Alveolar macrophages $\left(2 \times 10^{6}\right)$ were incubated for $30 \mathrm{~min}$ in the presence or absence of $10 \mu \mathrm{M} \mathrm{A23187}$, and eicosanoids were quantitated in medium by RIA. Each value is the mean $\pm S E$ of three individual experiments, each performed in duplicate.

for $\mathrm{LTB}_{4}, 5$-HETE, and free AA. Additional smaller peaks co-eluted with the lipoxygenase products $\mathrm{LTC}_{4}$ and 12-HETE, as well as the cyclooxygenase metabolites $\mathrm{TxB}_{2}, \mathrm{PGE}_{2}, \mathrm{PGD}_{2}$, and HHT. The eicosanoids $\mathrm{LTC}_{4}, \mathrm{LTB}_{4}$, and $\mathrm{TxB}_{2}$ wcre quantitated in unstimulated and A23187-stimulated cultures by RIA, and the mean values $(\mathrm{N}=3)$ are summarized in Table 1.

Effects of AF on A23187-induced AA metabolism. The effects of $1.5,3$, and $10 \mu \mathrm{g} / \mathrm{ml} \mathrm{AF} \mathrm{on} \mathrm{A23187-}$ induced macrophage AA metabolism are shown in the radioactivity $R P$-HPLC elution profiles depicted in Fig. 1, panels B, C, and D respectively. Ionophoreinduced $\mathrm{LTC}_{4}$ synthesis was eliminated at $1.5 \mu \mathrm{g} /$ ml AF, while A23187-induced $\mathrm{LTB}_{4}$ and 5-HETE synthesis were inhibited in parallel fashion by $\mathrm{AF}$ over the concentration range 1.5 to $10 \mu \mathrm{g} / \mathrm{ml}$. In contrast, at all doses tested, AF augmented A23187induced release of free $\mathrm{AA}$ as well as the cyclooxygenase products $\mathrm{TxB}_{2}$ and HHT. That this increase in radioactivity in $\mathrm{AA}, \mathrm{TxB}_{2}$, and $\mathrm{HHT}$ represents augmented phospholipase activity and not merely a shunting of $\left[{ }^{14} \mathrm{C}\right]$ arachidonate away from the 5lipoxygenase pathway is suggested by the greater total release of radiolabeled AA plus metabolites in cultures containing AF.

To assess in a more quantitative fashion the effects of AF on AM arachidonate metabolism, unlabeled cultures were incubated with $10 \mu \mathrm{M}$ A23187 in the presence and absence of various concentrations of AF and eicosanoids measured by RIA. As shown in Fig. 2, AF dose-dependently inhibited $\mathrm{LTC}_{4}$ $\left(\mathrm{IC}_{50} \sim 1 \mu \mathrm{g} / \mathrm{ml},>90 \%\right.$ inhibition at $\left.5 \mu \mathrm{g} / \mathrm{ml}\right)$ with greater potency than $\mathrm{LTB}_{4}\left(\mathrm{IC}_{50} \sim 4.3 \mu \mathrm{g} / \mathrm{ml},>90 \%\right.$ inhibition at $10 \mu \mathrm{g} / \mathrm{ml}$ ). AF dose-dependently augmented A23187-induced TxB $_{2}$ synthesis by as much as 5-fold over the same concentration range at which it inhibited LT synthesis (Fig. 2). Thus, both RP- 


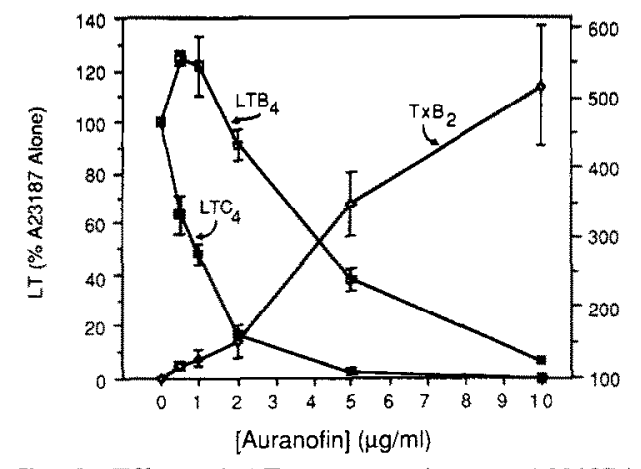

Fig. 2. Effect of AF concentration on A23187-induced synthesis of immunoreactive eicosanoids. Alveolar macro. phages were incubated for $30 \mathrm{~min}$ with $10 \mu \mathrm{M}$ A23187 either alone or in the presence of various concentrations of $\mathrm{AF}$. Immunoreactive $\mathrm{LTB}_{4}, \mathrm{LTC}_{4}$, and $\mathrm{TxB}_{2}$ were quantitated in culture medium, and the data are expressed as the percent of the quantities produced by A23187-stimulated cultures alone. Each point represents the mean $\pm S E$ from duplicate determinations in three independent experiments.

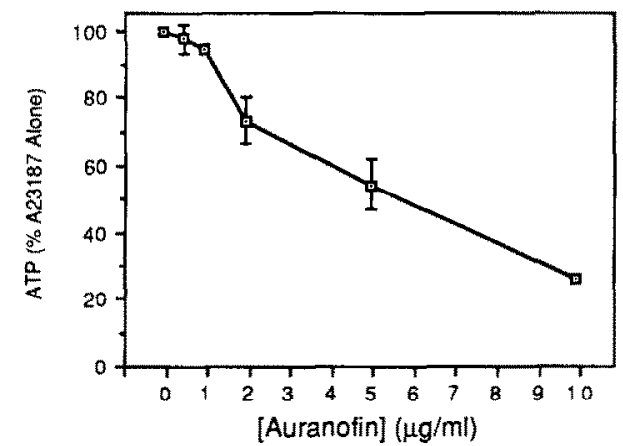

Fig. 3. Effect of AF concentration on ATP content in AM incubated with $A 23187$. Cultures were incubated for $30 \mathrm{~min}$ with $10 \mu \mathrm{M}$ A23187 alone or in the presence of AF at the indicated concentrations. Cellular ATP content was determined by the luciferase-luciferin method, and the results are expressed as the percent of the ATP content of cultures incubated with A23187 alone. Data represent the mean values $\pm S E$ from duplicate determinations in three independent experiments.

HPLC and RIA experiments demonstrated that AF: (1) inhibited LT synthesis while augmenting AA release and cyclooxygenase metabolism; and (2) inhibited the synthesis of $\mathrm{LTC}_{4}$ with greater potency than other 5-lipoxygenase eicosanoids.

Effects of AF on macrophage ATP content. Using the luciferase/luciferin method, we determined the ATP content of cells following $30 \mathrm{~min}$ of incubation with $10 \mu \mathrm{M}$ A23187 in the presence and absence of various concentrations of $\mathrm{AF}$. The effects of $\mathrm{AF}$ on cellular ATP levels were determined relative to the ATP content of AM cultures containing A23187 alone both to duplicate the conditions under which eicosanoid levels were evaluated and because we have observed previously an independent ATPdepleting effect for A23187 [19]. In the current study, the ATP content of AM cultures incubated with A23187 alone in the absence of AF was $269 \pm 77 \mathrm{pmol} / \mathrm{plate}(\mathrm{N}=3)$. As shown in Fig. 3,

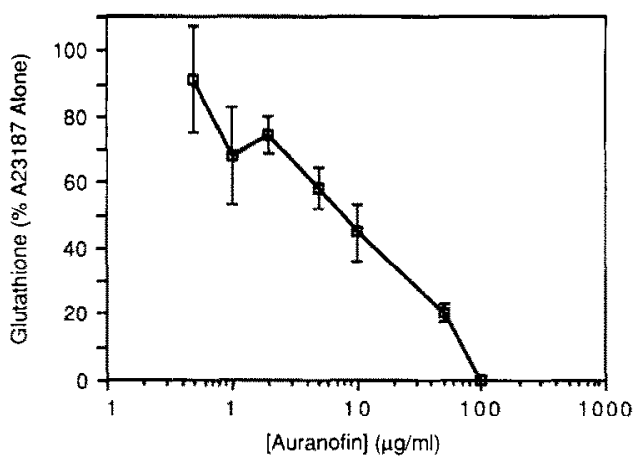

Fig. 4. Effect of AF concentration on intracellular glutathione content in AM incubated with A23187. Cultures were incubated for 30 min with $10 \mu \mathrm{M}$ A23187 alone or in the presence of $\mathrm{AF}$ at the indicated concentrations. Total glutathione content was determined by the glutathione reductase method, and results are expressed as the percent of the value determined for cultures incubated with $\mathrm{A} 23187$ alone. Data represent the mean values $\pm \mathrm{SE}$ from duplicate determinations in three independent experiments.

AF effected a dose-dependent depletion of cellular ATP, with an $\mathrm{IC}_{50} \sim 5.9 \mu \mathrm{g} / \mathrm{ml}$. To evaluate the potential for AF to interfere with the luciferase/ luciferin assay itself, different concentrations of $\mathrm{AF}$ were added directly to the assay buffer and ATP standard curves were generated. At final AF concentrations $\leqslant 10 \mu \mathrm{g} / \mathrm{ml}$ the gold compound had no effects on the ATP assay. Substantial interference with the measurement of ATP was observed at final AF concentrations $>10 \mu \mathrm{g} / \mathrm{ml}$, however (data not shown).

Effects of AF on macrophage glutathione content. To examine the possibility that the preferential inhibition by AF of $\mathrm{LTC}_{4}$ synthesis, as compared to $\mathrm{LTB}_{4}$ synthesis, was related to its ability to conjugate reduced glutathione, thereby decreasing the amount available for $\mathrm{LTC}_{4}$ synthesis [24], we measured total glutathione levels in AM cultures. The glutathione content following 30 min of incubation with A23187 in the absence of AF was $369 \pm 80 \mathrm{pmol} / \mathrm{plate}(\mathrm{N}=$ 3). Auranofin exposure depleted cellular glutathione in a dose-dependent fashion, albeit with a potency far less than that observed for the inhibition of $\mathrm{LTC}_{4}$ synthesis by AF; the $\mathrm{IC}_{50}$ for glutathione was $\sim 8 \mu \mathrm{g} /$ $\mathrm{ml}$, and $90 \%$ depletion was achieved at an AF concentration between 50 and $100 \mu \mathrm{g} / \mathrm{ml}(\mathrm{N}=3)$ (Fig. 4).

\section{DISCUSSION}

Although other investigators have examined the effects of AF on LT synthesis in several different cell types [8-10], no information is available regarding its effects on the synthesis of LT and other oxygenated metabolites of AA by macrophages. Yet this issue is particularly germane to understanding the antiinflammatory actions of AF, for the following reasons: (1) macrophages are thought to play a key role in the pathogenesis of chronic inflammatory disorders such as rheumatoid arthritis and asthma 
[11]; (2) the macrophage is generally regarded as an important target cell for the effects of chrysotherapy [13]; and (3) as compared to most other inflammatory cells, including the neutrophil, the macrophage has the capacity to synthesize larger quantities [25] as well as a more diverse spectrum of eicosanoids, including both $\mathrm{LTC}_{4}$ and $\mathrm{LTB}_{4}$ as well as a variety of cyclooxygenase metabolites [12]. We therefore undertook the present study to examine comprehensively the modulatory effects of AF on AA metabolism by the rat $\mathrm{AM}$, a cell whose profile of eicosanoid synthesis appears to closely resemble that of the human AM [26]. Ionophore A23187 was selected as an agonist because it is a potent stimulus for arachidonate metabolism via both cyclooxygenase and lipoxygenase pathways which bypasses the need for specific receptor interactions; as such, it can be regarded as a maximal stimulus of AA metabolism [27].

Analysis by RP-HPLC of the eicosanoid products of prelabeled AM indicated that A23187 stimulated the release of free $A A$ and its metabolism to 5-lipoxygenase products $\left(\mathrm{LTB}_{4}>5\right.$-HETE $>$ $\mathrm{LTC}_{4}$ ) to a greater extent than cyclooxygenase products $\left(\mathrm{HHT}=\mathrm{TxB}_{2}=\mathrm{PGD}_{2}>\mathrm{PGE}_{2}\right)$. Auranofin caused a parallel inhibition of both $\mathrm{LTB}_{4}$ and 5HETE synthesis by AM. This suggests that its inhibitory site of action was the 5-lipoxygenase enzyme itself, consistent with the findings of Honda and coworkers for intact neutrophils as well as cell-free homogenates [9]. Also in agreement with other reports [8,9], AF inhibited A23187-induced $\mathrm{LTC}_{4}$ synthesis $\left(\mathrm{IC}_{50} \sim 1 \mu \mathrm{g} / \mathrm{ml}\right)$ with greater potency than that observed for $\mathrm{LTB}_{4}$ synthesis $\left(\mathrm{IC}_{50} \sim 4.3 \mu \mathrm{g} / \mathrm{ml}\right)$, as revealed by both RP-HPLC and RIA analyses. The concentrations of $\mathrm{AF}$ at which we observed inhibition of LT synthesis are within the ranges reported by other investigators in blood neutrophils $[8,9]$ as well as basophils and lung mast cells $[10]$. In addition, as therapeutic AF concentrations in blood are in the $2-3 \mu \mathrm{g} / \mathrm{ml}$ range [28], and as gold has been shown to concentrate in macrophages at inflammatory sites [29], including alveolar macrophages [30], it is likely that the AF concentrations required for inhibition of $\mathrm{LTC}_{4}$, as well as $\mathrm{LTB}_{4}$, synthesis in the present study can be achieved locally at sites of inflammation in vivo.

It is important to note that the inhibitory effects of $\mathrm{AF}$ in our system were specific for the 5-lipoxygenase pathway; the cyclooxygenase pathway, as assessed by both RIA and RP-HPLC quantitation of $\mathrm{TxB}_{2}$, the major cyclooxygenase metabolite of the rat $\mathrm{AM}$ [14], was spared. Such specificity is consistent with the findings of Parente et al. [8] that AF inhibits neutrophil synthesis of $\mathrm{LT}$, but not $\mathrm{PGE}_{2}$. In fact, our data indicated that $\mathrm{A} 23187$-induced $\mathrm{TxB}_{2}$ synthesis was augmented over the same concentration range at which LT synthesis was inhibited. Analysis by RP-HPLC of the total products of prelabeled cells suggests that this reflects an actual augmentation of total phospholipase activity by AF, rather than mere shunting away from the 5-lipoxygenase pathway. In this regard, it is relevant that AF has been shown recently to stimulate phospholipase $\mathrm{C}$ activity in sonicates of a murine macrophage-like cell line [31].

ATP is a cofactor for 5-lipoxygenase $[15,16]$, and we have reported recently that ATP depletion accounts for the inhibition of AM 5-lipoxygenase caused by both unsaturated fatty acids [19] and hydrogen peroxide [32]. Because $\mathrm{AF}$ is thought to interfere with mitochondrial functions [33], we considered the possibility that an ATP-depleting effect may similarly play a role in its inhibition of 5-lipoxygenase. Our data suggest such a possibility, as the $\mathrm{IC}_{50}$ for ATP depletion was similar to that for $\mathrm{LTB}_{4}$ synthesis inhibition. A definitive causal link between the capacities of AF to inhibit 5-lipoxygenase and deplete cellular ATP remains to be established, however. We speculate that ATP depletion may also play a role in the cytotoxicity and alterations in plasma membrane morphology attributed to AF [33].

We next considered the possibility that the preferential inhibition by AF of macrophage $\mathrm{LTC}_{4}$, as opposed to LTB $_{4}$ and 5-HETE synthesis, may be related to the capacity to conjugate reduced glutathione based on its sulfhydryl reactivity [33]. We have demonstrated previously [14] that the sulfhydryl reactant $N$-ethylmaleimide depletes AM glutathione with the consequence that synthesis of LTC $_{4}$, which is formed by the glutathione transferase-catalyzed conjugation of reduced glutathione and LTA $_{4}$, is specifically inhibited. Our results demonstrated that AF did indeed deplete cellular glutathione, but the dose-response relationships for glutathione depletion and $\mathrm{LTC}_{4}$ inhibition suggest that these two phenomena were not causally related. A likely alternative explanation for the preferential inhibition of $\mathrm{LTC}_{4}$ synthesis is the higher $K_{m}$ value for $\mathrm{LTA}_{4}$ of glutathione transferase (catalyzing $\mathrm{LTC}_{4}$ synthesis) than of $\mathrm{LTA}_{4}$ hydrolase (catalyzing $\mathrm{LTB}_{4}$ synthesis) [9]. The consequence of such a difference

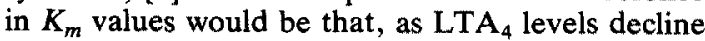
due to 5 -lipoxygenase inhibition, $\mathrm{LTC}_{4}$ synthesis would be more susceptible to substrate limitation than would $\mathrm{LTB}_{4}$ synthesis. In accord with this possibility, we have observed a similar preferential inhibition of $\mathrm{LTC}_{4}$ versus $\mathrm{LTB}_{4}$ synthesis in the settings of 5-lipoxygenase inhibition caused by both unsaturated fatty acids [19] and hydrogen peroxide [32].

Leukotriene $\mathrm{C}_{4}$ increases microvascular permeability, while $\mathrm{LTB}_{4}$ is a leukocyte chemoattractant which also stimulates leukocyte adherence and activation as well as modulating lymphocyte proliferation, differentiation, and function [7]. In addition, of particular relevance to the pathogenesis of asthma are the capacities of $\mathrm{LTB}_{4}$ to increase airway reactivity [34] and of $\mathrm{LTC}_{4}$ to cause bronchoconstriction [35] and stimulate mucus secretion in airways [36]. Our results indicate that, at therapeutic concentrations, $\mathrm{AF}$, an oral gold compound approved for use in the United States, acts in vitro as a selective inhibitor of macrophage 5-lipoxygenase metabolism. For all of these reasons, it is likely that inhibition of macrophage LT synthesis represents an important mechanism of action of AF in chronic inflammatory disorders such as rheumatoid arthritis and asthma.

Acknowledgements-The authors thank Dr. Bruce Wallin of Smith Kline \& French Laboratories for supplying auranofin, and Sharon Waltz for assistance in preparing the manuscript 


\section{REFERENCES}

1. Lipsky PE, Remission inducing therapy in rheumatoid arthritis. Am J Med 73 (Suppl): 40-49, 1983.

2. Yamauchi N, Suko M, Morita Y, Suzuki S, Ito K and Miyamoto $\mathrm{T}$, Decreased airway responsiveness to histamine in gold salt-treated guinea pigs. $J$ Allergy Clin Immunol 74: 802-807, 1984.

3. Bernstein DI, Bernstein IL, Bodenheimer SS and Pietruska RG, An open study of auranofin in the treatment of steroid-dependent asthma. J Allergy Clin Immunol 81: 6-16, 1988.

4. Muranaka M, Miyamoto T, Shida T, Kabe J, Makino $S$, Okumura H, Takeda K, Suzuki S and Horiuchi $Y$, Gold salt in the treatment of bronchial asthma-A double-blind study. Ann Allergy 40: 132-137, 1978.

5. Silver RM and Zvaifler NJ, Pathogenesis; Immunologic considerations. In: Rheumatoid Arthritis: Etiology, Diagnosis and Management (Eds. Utsinger PD, Zvaifler NJ and Ehrlich GE), pp. 71-89. J. B. Lipincott, Philadelphia, 1985.

6. O'Byrne PM, Hargreave FE and Kirby JG, Airway inflammation and hyperresponsiveness. Am Rev Respir Dis 136 (Suppl): 35-37, 1987.

7. Samuelsson B, Leukotrienes: Mediators of immediate hypersensitivity reactions and inflammation. Science 220: $568-575,1983$

8. Parente JE, Wong K, Davis P, Burka JF and Percy JS, Effects of gold compounds on leukotriene $\mathrm{B}_{4}$, leukotriene $C_{4}$, and prostaglandin $E_{2}$ production by polymorphonuclear leukocytes. I Rheumatol 13: 47-51, 1986.

9. Honda Z, Iizasa T, Morita Y, Matsuta K, Nishida $\mathrm{Y}$ and Miyamoto T, Differential inhibitory effects of auranofin on leukotriene $B_{4}$ and leukotriene $C_{4}$ formation by human polymorphonuclear leukocytes. Biochem Pharmacol 36: 1475-1481, 1987.

10. Marone G, Columbo M, Galeone D, Guidi G, KageySobotka A and Lichtenstein LM, Modulation of the release of histamine and arachidonic acid metabolites from human basophils and mast cells by auranofin. Agents Actions 18: 100-102, 1986.

11. Davies P, Bonney RJ, Humes JL and Kuehl FA Jr, The role of macrophage secretory products in chronic inflammatory processes. J Invest Dermatol 74: 292 $296,1980$.

12. MacDermot J, Kelsey CR, Waddell KA, Richmond R, Knight RK, Cole PJ, Collery CT, Landon DN and Blair IA, Synthesis of leukotriene $B_{4}$ and prostanoids by human alveolar macrophages: Analysis by gas chromatography/mass spectrometry. Prostaglandins 27: 163-178, 1984.

13. Lipsky PE, Ugai $K$ and Ziff $M$, Alterations in human monocyte structure and function induced by incubation with sodium thiomalate. J Rheumatol 6 (Suppl 5): 130 136, 1979.

14. Peters-Golden $\mathbf{M}$ and Shelly $\mathrm{C}$, Modulation of alveolar macrophage-derived 5-lipoxygenase products by the sulfhydryl reactant, $N$-ethylmaleimide. J Biol Chem 262: 10594-10600, 1987

15. Ochi K, Yoshimoto T, Yamamoto S, Taniguchi $\mathrm{K}$ and Miyamoto T, Arachidonate 5-lipoxygenase of guinea pig peritoneal polymorphonuclear leukocytes: Activation by adenosine 5'-triphosphate. $J$ Biol Chem 258 : 5754-5758, 1983.

16. Ahnfelt-Ronne I and Olsen UB, Leukotriene production in rat peritoneal leukocytes requires intact energy metabolism. Biochem Pharmacol 34: 30953100,1985

17. Peters-Golden $M$, Bathon J, Flores R, Ilirata $F$ and Newcombe DS, Glucocorticoid inhibition of zymosaninduced arachidonic acid release by rat alveolar macrophages. Am Rev Respir Dis 130: 803-809, 1984.
18. Westcott JY, Chang S, Balazy M, Stene DO, Pradelles $P$, Maclouf $J$, Voelkel NF and Murphy RC, Analysis of 6-keto $\mathrm{PGF}_{1 \alpha}, 5$-HETE, and $\mathrm{LTC}_{4}$ in rat lung: Comparison of GC/MS. RIA, and EIA. Prostaglandins 32: 857-873, 1986.

19. Peters-Golden $M$ and Shelly $C$, Inhibitory effect of exogenous arachidonic acid on alveolar macrophage 5 lipoxygenase metabolism: Role of ATP depletion. $J$ Immunol 140: 1958-1966, 1988.

20. Peters-Golden $M$ and Thebert $P$, Inhibition by methylprednisolone of zymosan-induced leukotriene synthesis in alveolar macrophages. Am Rev Respir Dis 135: 1020$1026,1987$.

21. Sporn PHS, Peters-Golden M and Simon RH, Hydrogen peroxide-induced arachidonic acid metabolism in the rat alveolar macrophage. Am Rev Respir Dis 137: 49-56, 1988.

22. Stanley PE and Williams SG, Use of the liquid scintillation spectrometer for determining adenosine triphosphate by the luciferase enzyme. Anal Biochem 29: 381-392, 1969.

23. Anderson ME, Determination of glutathione and glutathione disulfide in biological samples. Methods Enzymol 113: 548-555, 1985.

24. Rouzer CA, Scott WA, Griffith OW, Hamill AL and Cohn ZA, Arachidonic acid metabolism in glutathionedeficient macrophages. Proc Natl Acad Sci USA 79: 1621-1625, 1982.

25. Scott WA, Pawlowski NA, Murray HW, Andreach M, Zrike $J$ and Cohn ZA, Regulation of arachidonic acid metabolism by macrophage activation. J Exp Med 155 . 1148-1160, 1982

26. Balter MS, Eschenbacher WL and Peters-Golden M, Arachidonic acid metabolism in cultured alveolar macrophages from normal, atopic, and asthmatic subjects. Am Rev Respir Dis 138: 1134-1142, 1988.

27. Tripp CS. Mahoney $M$ and Needleman $P$, Calcium ionophore enables soluble agonists to stimulate macrophage 5-lipoxygenase. J Biol Chem 260: 5895-5898, 1985.

28. Dahl SL, Coleman ML, Williams HJ, Altz-Smith M, Cay DR, Paulus HE, Weinstein A and Kaplan S, Lack of correlation between gold concentrations and clinical response in patients with definite or classic rheumatoid arthritis receiving auranofin or gold sodium thiomalate. Arthritis Rheum 28: 1211-1218, 1985.

29. Vernon-Roberts B, Dore JL, Jessop JD and Henderson WJ, Selective concentration and localization of gold in macrophages of synovial and other tissues during and after chrystotherapy in rheumatoid paticnts. Ann Rheum Dis 35: 477-486, 1976.

30. Garcia JGN, Munim A, Nugent KM. Bishop M. HoieGarcia P. Parhami N and Keogh BA, Alveolar macrophage gold retention in rheumatoid arthritis. $J$ Rheumatol 14: 435-438, 1987

31. Snyder RM, Mirabelli CK, Clark MA, Ziegler JT and Crooke ST, Effect of auranofin and other gold complexes on the activity of phospholipase C. Mol Pharmacol 32: 437-442, 1987

32. Sporn PHS and Peters-Golden M, Hydrogen peroxide inhibits alveolar macrophage 5-lipoxygenase metabolism in association with depletion of ATP. J Biol Chem 263: 14776-14783, 1988.

33. Snyder RM, Mirabelli CK and Crooke ST, The cellular pharmacology of auranofin. Semin Arthritis Rheum 17: 71-80, 1987.

34. O'Byrne PM, Leikauf GD, Aizawa H, Bethel RA, Ueki IF, Holtzman MJ and Nadel JA, Leukotriene $\mathrm{B}_{4}$ induces airway hyperresponsiveness in dogs. $J$ Appl Physiol 59: 1941-1946, 1985.

35. Holroyde MC, Altounyan REC, Cole M, Dixon M and Elliott $\mathrm{EV}$, Bronchoconstriction produced in man by leukotrienes C and D. Lancet 2: 17-18, 1981. 
36. Shelhamer JH, Marom Z, Sun F, Bach MK and Kaliner $M$, The effects of arachinoids and leukotrienes on the release of mucus from human airways. Chest $\mathbf{8 1}$ (Suppl): 36-37, 1982. 